\title{
Spatial behavior of two coral reef fishes within a Caribbean Marine Protected Area
}

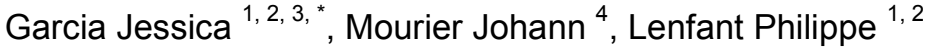

${ }^{1}$ Univ. Perpignan Via Domitia, CEntre de Formation et de Recherche sur les Environnements Méditerranéens, UMR 5110, F-66860, Perpignan, France

${ }^{2}$ CNRS, CEntre de Formation et de Recherche sur les Environnements Méditerranéens, UMR 5110, F66860, Perpignan, France

${ }^{3}$ IFREMER, UR Lagons Ecosystèmes \& Aquaculture Durable, BP 2059, 98846 Nouméa Cedex, New Caledonia

${ }^{4}$ LabEx « CORAIL » - USR 3278 CNRS-EPHE, Centre de Recherche Insulaire et Observatoire de I'Environnement (CRIOBE), BP 1013 - 98 729, Papetoai, Moorea, French Polynesia

* Corresponding author : Jessica Garcia, email address : jessicagarcia.mpa@gmail.com

\begin{abstract}
:
A better understanding of the key ecological processes of marine organisms is fundamental to improving design and effective implementation of marine protected areas (MPAs) and marine biodiversity. The movement behavior of coral reef fish is a complex mechanism that is highly linked to species life-history traits, predation risk and food resources. We used passive acoustic telemetry to study monthly, daily and hourly movement patterns and space use in two species, Schoolmaster snapper (Lutjanus apodus) and Stoplight parrotfish (Sparisoma viride). We investigated the spatial overlap between the two species and compared intra-specific spatial overlap between day and night. Presence-absence models showed different diel presence and habitat use patterns between the two species. We constructed a spatial network of the movement patterns, which showed that for both species when fish were detected by the array of receivers most movements were made around the coral reef habitat while occasionally moving to silt habitats. Our results show that most individuals made predictable daily crepuscular migrations between different locations and habitat types, although individual behavioral changes were observed for some individuals across time. Our study also highlights the necessity to consider multiple species during MPA implementation and to take into account the specific biological and ecological traits of each species. The low number of fish detected within the receiver array, as well as the intraspecific variability observed in this study, highlight the need to compare results across species and individuals to be used for MPA management.
\end{abstract}




\section{Highlights}

- Two species of tropical reef fish showed contrasting spatial behaviour. Models revealed interspecific diel differences in presence and habitat use.

- Fish shifted their activity and use of habitats between day and

night. Multi-specific approaches increase our understanding of fish spatial use in MPAs.

Keywords : Spatial behavior, Acoustic monitoring, Individual variability, Lutjanus apodus, Sparisoma viride, Martinique

\section{Introduction}

Animal movement plays a fundamental role in the structure and dynamics of populations, communities and ecosystems (Nathan et al., 2008) and is driven by key ecological processes that influence how animals occupy their environment at multiple spatial and temporal scales (Hitt et al., 2011a). The main difficulty in the study of marine animal movement resides in the complexity of choosing appropriate spatio-temporal scales and matching technology to that appropriate scale. In many studies, fish movement patterns have been investigated at various scales ranging from meters to kilometers and from a few minutes to several years (Quinn and Brodeur, 1991; Pittman and McAlpine, 2003). For example, fish often display diel migrations at sunrise and sunset between spatially distinct diurnal and nocturnal habitats inside their home range (McFarland et al., 1979; Krumme, 2009, Hitt el al., 2011b). Studies have revealed this phenomenon for different fish families, such as Haemulids (Ogden and Ehrlich, 1977; Rooker and Dennis, 1991; Nagelkerken et al., 2000), Lutjanids (Nagelkerken et al., 2000; Verweii et al., 2007; Hitt et al., 2011a, 2011b), Lethrinids (Chateau and Wantiez, 2008a) and Labrids (Ogden and Buckman, 1973; Dubin and Baker, 1982). However, a better understanding of spatiotemporal movement patterns at small and medium-scales can provide fundamental information to improve marine protected area (MPA) management. The parameters characterizing the design of MPAs such as size, shape and number of MPAs as well as optimal spacing between them should be determined by accounting for fish mobility and behavior (Claudet et al., 2008). The conservation of a species that spends a large amount of time outside a MPA will be less efficient than species whose ranges are within MPA boundaries (Chateau and Wantiez, 2008b; Meyer et al., 2010). Small marine reserves may not contain all essential habitats (refuge, nutrition and reproduction) and the complete home ranges of target fish species, leading to partial protection (Abecasis et al., 2015). Most studies on movement patterns have focused on residence time, home range size and site fidelity but few studies have investigated the movement patterns and habitat use at finer-scales (Toole and Szedlmayer 2011). Acoustic monitoring has been extensively used to determine movement patterns, habitat utilization and home range size (Meyer et al., 2000; Lowe et al., 2003; Topping et al. 2005; Marshell et al., 2011; Garcia et al., 2014). However, the performance of receivers, as a result diel detection patterns, could be affected by the number of tagged individuals within the array (Simpfendorfer et al., 2008) and the

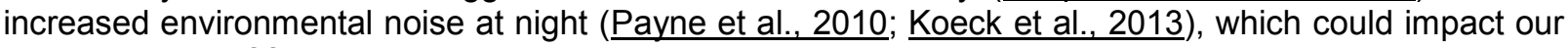
interpretations of fish behaviour. 
A recent study (Garcia et al., 2014) used two complementary methods (acoustic telemetry and external

60

61 tagging) to investigate movement patterns, home range and site fidelity of three fish species (Acanthurus chirurgus, Lutjanus apodus and Sparisoma viride) in a Martinique MPA. These authors found that most fish used a small preferential site $\left(\approx 650 \mathrm{~m}^{2}\right)$ located on a rocky reef composed of sand, corals and seagrass for a long period time (2 months to 1 year) and used silty substrate and artificial reef like corridors during short periods of time (1-4 days). Using active tracking, the authors determined the home range location and size for these species. However, the study did not include the diel dimension of these patterns of movement. In the present study, using the same dataset as Garcia et al., (2014), we aimed to determine habitat use and movements for L. apodus and $S$. viride at a finer spatial scale. The aims were to: 1) quantify spatial overlap between L. apodus and S. viride, 2) determine the presence probability for each species on each habitat (coral, seagrass, soft bottom or artificial reef) and movements within the study area, 3) investigate potential shifts in habitat use between day and night and finally 4) determine if fish show cyclical patterns (hourly, daily and seasonal) of space use. Unfortunately, acoustic data obtained for A. chirurgus by Garcia et al., (2014) were insufficient to be used for spatio-temporal analysis at this fine scale.

L. apodus and S. viride are commercial abundant species in the Caribbean and are highly targeted by artisanal fishers (Rooker, 1995; Nagelkerken et al., 2002; Choat et al., 2003). These two species have different trophic levels (carnivorous and herbivorous, respectively) and mobility. On the basis of previous studies on movements of these species and their ecological and biological differences, we hypothesized that these two species would have different temporal and spatial habitat utilization in the study area. Indeed, Hitt et al. (2011b) demonstrated using active tracking that $L$. apodus makes twilight migrations from its daytime seagrass feeding zones toward its nighttime refuge areas in the coral reef. However, acoustic telemetry has never been used to study Sparisoma viride. The only information available regarding the movement of this species is provided by an experimental mark-release-recapture study conducted in a Jamaican marine reserve which demonstrated highly variable movement patterns for S. viride with individuals recaptured multiple times at the same site (within 100 m), whereas others were caught more than $10 \mathrm{~km}$ away outside the reserve (Munro 2000). Better knowledge of the spatial behavior of these two species at finer spatio-temporal scale is necessary to implement efficient protection for these exploited fish species in Martinique.

\section{Materials and methods}

\section{Study site}


The work was conducted in a coastal MPA located near the village of Robert in Martinique (Lesser Antilles; $14^{\circ} 36^{\prime}$ N, $61^{\circ} 32^{\prime}$ W, Fig. 1). Eight no-take zones (NTZ) were created and managed by local fishermen who decide on the opening and closing of fishing within these MPAs. Some MPAs are opened once a year but others have never been opened since their creation. Our study was carried out in Robert MPA (Fig. 1), which has never been opened to fishing since its establishment in 2000. The whole protected area covers 956 ha. The habitat is not continuous within the MPA and is dominated by silty substrate. Nevertheless, three patches of rocky substrates $\left(\sim 650 \mathrm{~m}^{2}\right)$ are present inside the MPA and are composed of coral, gorgonians, sponges, seagrass and algae (Fig. 1). The fish community is strongly concentrated within these zones (Garcia et al. 2014).

\section{Acoustic array}

From December 2009 to November 2011, we deployed 20 VR2W acoustic receivers (® Vemco) in Robert Bay forming 3 lines of receivers. We used mobile tracking surveys using VR100 to determine fishes preferred sites and the results were presented in Garcia et al. (2014). Five supplementary receivers were added to the network from December 2010 to November 2011 at the preferred sites previously determined by the tracking mobile system to determine $S$. viride and L. apodus diel patterns of movements within this habitat (Fig. 1). We conducted range tests at different locations of the study area (See Garcia et al. (2014) for more details) showing a maximum radius of $100 \mathrm{~m}$ for the receivers located on rocky substrates (R310, R307, R309, R308, R306) and $150 \mathrm{~m}$ for all the other receivers located on silty substrates.

\section{Fish capture and transmitter deployment}

Fish were caught using Antillean traps and immediately transported back to the laboratory where they were placed in a holding tank. They were then equipped with VEMCO V7-4L ${ }^{\circledR}$ ultrasonic coded transmitters. These tags pulse randomly every 120-360 seconds. Nominal battery life was expected to last over 412 days according to the manufacturer. To reduce the impact of transmitters on fish mobility, the selected ratio of fish weight to transmitter weight was kept below 1\%. All fish were captured inside the MPA because of overfishing outside the MPA, leading to difficulty in catching sufficiently large adult fish.

Each fish $(\mathrm{N}=68)$ was anesthetized with clove oil at a concentration of $0.02 \mathrm{ml} \mathrm{l}^{-1}$ and the transmitter was inserted into the peritoneal cavity through a small incision $(1 \mathrm{~cm})$. To provide visual identification of these fish after their capture, we also implanted an external T-tag (Floy Tags Inc.). Each individual was maintained in captivity for 7 days, including one acclimation day, one operation day, 2 days for safe recovery, followed by 3 days of feeding. All individuals were released at the capture site along the coral reef patches (Fig. 1).

\section{Data analysis}


Receiver performance

119

120

121

122

123

124

125

126

127

128

129

We first filtered our raw detection data and deleted false detections. Data files downloaded from VR2W receivers contained a number of parameters that can be used to investigate the receiver performance during the deployment (Simpfendorfer et al., 2008). Three metrics were therefore calculated: code detection efficiency (cde $=D / S)$, rejection efficiency $(r c=C / S)$ and noise quotient $(n q=P-(S . c l))-$ where $D$ is the number of valid detections, $S$ is the number of synchs, $C$ is the number of codes rejected because of invalid checksums, $P$ is the number of pulses detected and $c l$ is the number of pulses used to make a valid code (detailed analysis are presented in Simpfendorfer et al., 2008).

\section{Temporal analysis}

We calculated the number of days each fish was detected in the array as well as the proportion of days it was detected during the experiment (i.e. the number of days from the time of release after tagging to the day the receivers were removed from the water; Meyer et al., (2010).

We used time series analysis and fast Fourier transformations (FFTs) with Hamming window smoothing (Statistica version 6.0) to describe the cyclicity in site utilization for each individual. For each fish, we selected the receiver that most frequently detected that individual and pooled detections from that receiver into hourly bins (Meyer et al., 2010).

\section{Spatial analysis}

Our first approach was to compare space use between species (Meyer et al. 2010). Based on the number of days each individual was detected at each receiver, we generated a Bray Curtis similarity matrix and used a one-way ANOSIM (Primer-E Version 6, Plymouth, UK) to assess the degree of spatial overlap between both species. This statistical test quantifies spatial overlap between fish species and compares them against 999 random permutations. In addition, ANOSIM generates a Global R statistic (Clarke and Warwick, 2001) and a pvalue. If $\mathrm{p}<0.05$, then the species do not show overlap and $\mathrm{R}$ indicates the degree of similarity between species groups. We used $\mathrm{R}$ as an indicator of the degree of overlap between the groups $(\mathrm{R}<0.25$ : high overlap, $\mathrm{R}=0.25$ 0.75: medium overlap, R>0.75: low overlap). We used non-metric multidimensional scaling ordinations (nMDS) to obtain a visual interpretation of space utilization and spatial overlap between species.

We then aimed to compare individual diurnal and nocturnal space use for each species (Meyer et al. 2010). We calculated the number of nocturnal (from 1659 to $0500 \mathrm{hrs)} \mathrm{and} \mathrm{diurnal} \mathrm{(from} 0501$ to $1700 \mathrm{hrs)}$ detections per hour for each individual of each species. These periods corresponded to the annual average times between sunrise and sunset in the study area. Using these individual measures, we generated a Bray-Curtis 

similarity matrix and used a one-way ANOSIM (Primer-E Version 6, Plymouth, UK) as described above. We used non-metric multidimensional scaling ordinations (nMDS) to obtain a visual interpretation of diurnal and nocturnal space use for each species. We also determined the number of receivers visited by the fish. Individuals were not tagged at the same time.

We used a generalized linear mixed-effects modeling framework (GLMM) that incorporates both random and fixed variables, to examine the effects of time of year (calendar month), location (receiver) and time of day (hour) on the presence of fish in the studied area. For each species, acoustic Tag ID was incorporated as a random variable, rather than fixed factor, to account for pseudoreplication and enable model prediction to extend to the rest of the population. Analysis was implemented using the lmer() function in the lme4 package (Bates et al. 2011) within R version 2.5.1 (R Core Development Team 2012). The analysis used a binomial error structure with a logit link function. The binomial dependent variable was coded with a value of one if a fish was detected ('present') and zero when no fish were detected ('absent'). 'Presence' was evaluated per hour for each level of the qualitative variables 'Hour' and 'Receiver', and was modeled for the duration of the monitoring period. The other qualitative variable was 'Month'. We used model selection and model-averaging procedures from the MuMIn R package based on Akaike's Information Criterion corrected for small sample sizes (AICc) (Bardo 2013).

\section{Spatial network analysis}

In order to identify the patterns of movements and preferred area used by the two fish species, we used a spatial network analysis. Instead of using a spatial network based on counts of directed movements between receivers as proposed by Jacoby et al., (2012), which ignores temporal characteristics of movements such as residency periods, we followed the Empirical derived Markov chain (EDMC) analysis proposed by Stehfest et al. (2015) which takes into account this temporal dimension. A Markov chain is a random process that undergoes transitions from one state to another (in our case from receiver to receiver) on a state space. For each species, the raw series of acoustic detections was organized into an hourly detection time series for each fish. For every hourly time step, if the fish was detected by a receiver then the receiver ID was assigned to the state and if the fish was not detected it was assigned an absent state. Movement count matrices were then computed for each individual fish containing movements between each receiver as well as the movements from each state to itself (residency periods; the fish stay at the same receiver) and movements into absent state (transition periods outside of the detection range of receivers). The Markov chain approach requires a number of assumptions including that (1) the probability of moving from any given state to the next depends on the current state but not on the 
preceding ones, (2) individuals move independently from each other, (3) transition probabilities between states do not change over time and finally (4) tagged individuals represent a random sample of the population in the study area. Transition probability matrices were constructed by dividing each number of transitions made from one state to another or itself by the number of transitions made from the state. To identify preferred use of locations (i.e. receivers) from the movement network, we calculated the eigenvector centrality of each node which is a measure not only of the centrality of a state, but also of the centrality of the states it is connected too (see Stehfest et al. 2015). It is calculated as the dominant eigenvector of the movement network or adjacency matrix and is equivalent to the weighted proportion of the total number of paths in a network going to or coming from a given node (Newman 2004). To test the difference between movements of the two species, we used a Mantel test between the two transition probability matrices.

\section{Results}

Receiver performance

Overall the average receiver code detection efficiency (mean number of detections per synch) was 0.128 indicating that on average only $12.8 \%$ of the codes transmitted were detected. The mean rejection coefficient was consistently low $\left(0.0022\right.$ rejections. synch $\left.^{-1}\right)$ and the mean noise quotient was 7112 suggesting that the environmental noise may have affected the receiver efficiency in the study area. While detection efficiency was low, the rejection coefficient was also very low indicating that only small proportions of codes received were rejected because of invalid checksums. It is therefore likely that most of the code detection inefficiency of the receivers was the result of incomplete code sequences rather than rejected full sequences. The partial reception of code sequences may be due to environmental characteristics such as the low depth of receivers around the reef or due to individual movements during transmission. In this study, as we used 1 hour time intervals in most analyses, the impact of missed code detections on our data analysis is likely to be low.

\section{Acoustic tagging}

We tagged and released 27 S. viride and 41 L. apodus. However, we detected only 12 L. apodus and 11 S. viride (Table 1), and only 7 L. apodus and 7 S. viride presented a percentage of time spent within the array above 9\%. L. apodus were monitored for periods of 2 to 208 days (mean $=87.3$ days, $\mathrm{SD}=92.9)$ and $S$. viride for 5 to 215 days $($ mean $=67.7$ days, $\mathrm{SD}=71.9)($ Table 1$)$. L. apodus were detected from 1.5 to $100 \%$ of days within the array $($ mean $=46.3 \%, \mathrm{SD}=0.5)$ and $S$. viride from 2.3 to $99.5 \%$ of days $($ mean $=29.6 \%, \mathrm{SD}=0.3)$ (Table 1). Most fish remained in one patch of rocky substrate $\left(650 \mathrm{~m}^{2}\right)$. Despite overlap between detection ranges of some receivers, no individuals were detected by two receivers simultaneously. 
Spatio-temporal analysis

All 33 fish detected during this study, were recorded between December 2010 and November 2011 (Fig.

2, Fig. 3). The results of the ANOSIM analysis showed that there were statistical differences in space utilization ( $\mathrm{p}<0.05$ ) between $S$. viride and L. apodus, although overlap was still high $(\mathrm{R}=0.103)$ (Fig. 4a). Three receivers detected most of the fish along a rocky substrate: R307, R308 and R309 (Fig. 2) and separated by less $500 \mathrm{~m}$ (Fig. 1). We observed that some individuals (ID\#162, ID\#169, ID\#176, ID\#265 and ID\#167) made sunset and sunrise movements between different sites but unfortunately some day or night locations remain unidentified

\section{Lutjanus apodus}

Global movement analysis

The best fitting GLMM models incorporated the covariates Hour, Month and Receiver (Table 2). array and higher at coral patches (receivers R307, R308 and R309) than other habitats (Fig. 5, Supplementary Table 1). L. apodus showed a peak in its probability of presence in February compared to the other months (Supplementary Table 1).

In general, our data show high intra-species variability in movement patterns between day and night. The majority of movements between receivers occurred at sunset and sunrise. The results from the ANOSIM showed a significant difference $(\mathrm{R}=0.608, \mathrm{p}=0.001)$ between diurnal and nocturnal patterns of space use for all L. apodus (Fig. 4b). The results of the Fast Fourier analysis revealed that individuals ID\#169, ID\#176, ID\#308, ID\#265 and ID\#167 had a 24-h cyclical pattern of movement (Table 1). Individual ID\#265 had a supplementary dominant peak at $12 \mathrm{~h}$ and individual ID\#167 had a peak at $8 \mathrm{~h}$. Fish ID\#162 and ID\#270 did not reveal any cyclical patterns.

Movements within coral patches

Some fish displayed a shift in their diurnal and nocturnal site utilization during the study period (Figs 2 and 5). For example, Individual ID\#176 appeared to reside near receiver R307 during the day and move to receiver R309 at night but it stopped moving to R307 during the day between August and November. Moreover, individual ID\#167 stayed at the same receiver during the day and it moved to an unidentified site during the night. However, it changed its behavior between September and October 2011 and stayed at receiver R309 between September and October 2011, and was also frequently detected by receiver R307 during the day in August 2011. As another example, ID\#169 resided at R309 during the night but was almost never detected during the day. 
Movements to the artificial reef

The artificial reef (R306) seems to play an important role in the spatial behavior for some fish because it recorded the last detections of most fish that left the MPA. Indeed, individuals ID\#308 and ID\#265 were evenly detected on the artificial reef at the end of the rocky substrate between January and May 2011. This site was sporadically (19 pings) used by one L. apodus (ID\#265), and frequently used by individual ID\#308 (88.5\% of total detections). The receiver at this site recorded the last detections of both fish (Fig. 2). In addition, four individuals (ID\#154, ID\#160, ID\#164 and ID\#170) have been detected 2-3 times by the second barrier of receivers located outside the MPA. These fish were not detected again within the MPA.

\section{Sparisoma viride}

Global movement

The best fitting GLMM model incorporated Hour, Month and Receiver as covariates (Table 2). Hourly probability of presence was higher within twilight periods with a peak of presence at 5-6 am and 5-6 pm (Fig. 6). S. viride was also more present at coral patches but non-negligibly used seagrass beds (R310) and more surprisingly silty substrates (R298 and R299) (Fig. 5). S. viride showed a peak of presence in March (Supplementary Table 1).

Temporal patterns of stoplight parrotfish were highly variable among individuals (Table 1). Three fish (ID\#151, ID\#173, and ID\#178) were detected frequently (>63\% of the time) within the array (Table 1). In contrast, individuals ID\#142, ID\#144 and ID\#180 were less frequently detected $(<4.6 \%$ of the total time; Table 1). Three fish (ID\#151, ID\#173, and ID\#178) showed cyclical periods of 24, 12, 8, 6 and $4 \mathrm{~h}$ (Table 1) as revealed by FFT analysis. In addition, there was no overlap between diurnal and nocturnal spatial patterns of $S$. viride (ANOSIM, R=0.712, p=0.001) (Fig. 4c). Only one fish (ID\#150) was detected by one receiver located outside the MPA and was not detected again within the MPA.

\section{Movements within coral patches}

For S. viride, diel detection patterns varied consistently between individuals (Fig. 3 and 5). Three individuals (ID\#146, ID\#173 and ID\#178) were frequently detected during the day but never at night. Receivers R309 and R307 predominantly detected these fish. In addition, they occasionally moved to receiver R310 (1-19 pings). Nevertheless, individual ID\#151 was detected almost only at night (1659 to $0500 \mathrm{hrs)} \mathrm{as} \mathrm{well} \mathrm{as} \mathrm{at} \mathrm{sunset} \mathrm{and}$ sunrise at R307, but only a few detections (6 pings) were recorded during the daytime. One individual (ID\#165) did not display a diel pattern. This fish was mainly detected on silty substrate by $R 299\left(\mathrm{~F}_{\mathrm{d}}=90.7 \%\right.$ of total detection) and also occasionally moved to R298 (2 detections) and R297 (12 detections). This fish was the only 
one to use these three receivers, which were located on silty substrates at a depth of 20 meters. Individuals ID\#146, ID\#178 and ID\#173 moved to receiver R309 during May. Three individuals (ID\#151, ID\#178 and ID\#173) were detected from 15th to 19th of April 2011 by receiver R310.

Movements on silty substrates

Some individual S. viride moved on silty substrates (R298; R297; R298 and R269) located on the boundaries of the MPA and kept the same location for consecutive days (Fig. 3). This behavior was observed for four individuals and exclusively in males. The fish were detected 1 to 8 times a day over 1-8 consecutive days.

\section{Network analysis}

For L. apodus, most hourly direct movements occurred between receiver R307, R308, and R309 located all on coral patches (Fig. 6) with receiver R309 being the most central node of the network as shown by the highest eigenvector centrality value (0.15). However, L. apodus were most likely to be in the spatially absent states (summed probabilities $=0.89$ ). Out of the detectable states, R309 had the highest rank, followed by state R308, then R307 (Fig. 6). States R306 (artificial reef) and R310 (coral patch) were rarely reached.

For S. viride, most movements occurred between R306 (artificial reef) and R299 (silty substrate) although the most central node was R307 (coral patch) given the movements between the trio of receivers R307, R309 and R310 located all on coral patches (Fig. 6). Like L. apodus, S. viride were most likely to be in the spatially absent states (summed probabilities $=0.94$ ). S. viride similarly used receivers R307 and R309 but also R310 located on the other side of the reef. However, they also used a larger number of receivers than L. apodus, often being present in receivers R297, R299 (silty substrate) and R306 (artificial reef) (Fig. 6). These movements were driven by the short-term activities of 4 individual fish in this area. There was also no clear significant similarity between patterns of movements of both species (Mantel test: $r=0.04, \mathrm{P}=0.058$ ).

\section{Discussion}

In this study, we provide evidence for inter- and intra-specific differences in spatio-temporal patterns of reef fish movements. Individual variability can be influenced by species life-history traits, risk of predation, competition and food resources (Hitt et al., 2011a, 2011b). In addition, our analysis was applied to a small number of individuals, which may increase variability in the results, which is a recurrent problem with acoustic telemetry studies (Luo et al., 2009). Nevertheless, our results highlight several patterns of space use at different temporal scales among tagged fish. 
We observed that $S$. viride individuals often visit habitats composed of silt and mud where feeding or shelter habitats are absent. These results are surprising for $S$. viride because this species usually lives in coral reef and mangrove habitats (Bruggemann et al. 1994). Female parrotfish can share the same territory, while males also share territory but show intraspecific competition against other males to defend their harem. Therefore, male $S$. viride (specifically young males) tend to cover a larger home range than females (van Rooij et al., 1996; Mumby et al., 2002) and have more exploratory movements than females. Another explanation could be that fish were predated. However, this possibility seems to be unlikely as tagged fish had been detected over long periods (2-6 months) and ingested acoustic tags by predators are generally expulsed within a few days (Armstrong et al., 1992). Additional studies are required to confirm our finding that $S$. viride visits silt habitats for a period of consecutive days (1-8 days). These two species did not have the same spatial utilization of the habitat (ANOSIM: $\mathrm{p}$ <.05) but they have a high overlap ( $\mathrm{R}=0.13$; Fig 4). This result can be explained if there are many replicates at each site (Clark and Warwick 2001). In our analysis, we have 33 fish detected by 18 different receivers. The number of replicates is high which may explain the $\mathrm{R}$ value. Consequently, it is likely that there habitat use by the two species is only weakly overlapped and a low signal.

For both species, we observed that many fish repeatedly shift locations between day and night for several months (4-7 months). Most individuals had a preferred diurnal and nocturnal site, making daily crepuscular migrations between sites when they were within the range of the receivers. This behavior, also called “commuting", has been described in other coral reef fish species (Meyer and Holland, 2005; Marshell et al., 2011; Taylor and Mills, 2013). Some of these individuals interrupted their daily crepuscular movements at some periods of the year. These behavioral modifications appeared to take place over a period of 1 to 3 months and then the fish returned to twilight movement patterns. The unexpected modifications of diel movements could be due to potential spawning migrations (Taylor and Mills, 2013), although this hypothesis remains difficult to confirm with our present data. Most studies on L. apodus were conducted over 3 months using external tags or mobile acoustic tracking (Verweij et al., 2007; Hitt et al., 2011a) and showed evidence of variability in patterns of space use between different individuals. behavior in reef fish demonstrating cyclical diel movement patterns. Unfortunately, we did not use a control tag to test the influence of diel variations on detection efficiency. Previous studies showed that the variations of diel detection patterns observed could be the result the increased of environmental noise at night that may decrease detection probabilities (Payne et al., 2010; Koeck et al., 2013). Environmental noise could be created by an 
increase in biological activity (Radford et al. 2008). In our study, only individuals ID\#162 and ID\#165 were detected by the same receiver during all hours of the day (Fig. 2; Fig 3). For these two individuals no cyclical diel patterns were revealed by the FFT analysis. Other individuals (ID\#176 and ID\#167) were detected by the same receiver during all hours of the day but simply over short periods ( $<5$ days) and showed cyclical diel movement patterns (Fig. 2). Consequently, it remains difficult to confirm the diel patterns hypothesis for these individuals. However, the results from the GLMM of presence-absence data show distinct daily presence patterns between species (Fig. 5) that is unlikely a result of environmental noise on detection probabilities. Globally, L. apodus tended to increase their presence at receivers during the night while $S$. viride showed an increased probability of presence during sunrise and sunset periods (Fig. 5).

For other individuals that moved between different receivers, there was no ambiguity in the presence of diel movement patterns. These movement patterns have previously been observed for L. apodus (Rooker and Denis, 1991; Nagelkerken et al., 2000; Verweij et al., 2007; Hitt et al., 2011a) and for the Scarine labrids (Meyer et al. 2010; Welsh and Bellwood, 2012; Howard et al., 2013) and were attributed to homing or sheltering. In other species, these diel patterns have been widely documented (Lowe et al. 2003; Meyer 2007), with fish moving between feeding and refuge areas at sunset and sunrise (Dahlgren and Eggleston 2000; Meyer et al. 2010; Welsh and Bellwood 2012). The variability of the movements observed in other studies was frequently attributed to the availability and proximity of foraging areas. In the present study, the narrow band of rocky substrate is composed of patchy corals, sponges, seagrass and algae at the depth of 3 to $8 \mathrm{~m}$, but is also damaged by a high level of sedimentation. In addition, this area is surrounded by anoxic mud at 9 to $20 \mathrm{~m}$ depth, which may isolate this habitat patch. However, although this rocky substrate concentrates common marine organisms, it appears unlikely that it can supply sufficient foraging or refuge areas for all fish present in this zone. We therefore hypothesize that some fish move to other sites, such as nearby mangroves or other coral patches (Fig. 1).

Of the 68 fish tagged, only one third were detected and half of the monitored individuals were detected less than $3 \%$ of the time within the array of receivers (Table 1) with $85 \%$ of tagged fish being transitory in the study area. In a previous study, Garcia et al., (2014) used a mobile tracking system (VR100) to follow the individuals outside of the study area. No tracked individuals were found outside of the study area (in /out MPA). These fish may have moved outside the receiver array after release and found another preferred site; alternatively, they may be less site-attached than the others and have no specific shelter site. It is very likely that these individuals showed preferences to other sites that were not covered by the range of our receivers. Meyer et 
al. (2010) tagged 70 individuals but only 53 fish were detected in a period varying from 1 to 612 days (median=

358 52 days). Our results can be explained by the degraded and restricted rocky habitat present on the study area. This zone seems unfavorable or of an insufficient size to establish a residency site for all L. apodus and S. viride individuals. However, it seems that only some individuals could shelter during long periods in the study area. Moreover, the last detections recorded for 12 tagged fish were before the end of transmitter battery life and 6 of these were detected for the last time outside of the MPA. Previous studies have shown that the number of fish detected declined soon after release and during all the monitoring period (Chateau and Wantiez 2008b; Meyer et al., 2010). Many reasons could explain this fact: 1) premature failure of battery life, 2) effect of tagging procedures (increased mortality or tag expulsion), 3) fishing or natural mortality 4) relocation to another site (Meyer et al., 2010). Our previous study showed that fish can leave the bay and be recaptured several kilometers away (Garcia et al., 2014), a finding which could support the last hypothesis.

Despite the small number of detected fish, we observed similar patterns of movements and simultaneous movements for 2-3 individuals for each species. There are a number of potential explanations for these simultaneous spatial temporal movements: 1) spawning seasons, 2) changes of environmental conditions (precipitations, high wind, and variability of physico-chemical water conditions), 3) anthropogenic activities (boat noise, nautical activities), 4) predation pressure, 5) competitors or 6) temporal dietary requirements (Hitt et al., 2011b).

The probability of an individual fish being outside receiver range in the experimental study were high for both species suggesting that fish spent a large proportion of their time outside of the array. It also suggests that, when travelling, fish might use different routes and use random walk strategies rather than directed walks. Random walks are used when the locations of resources are unknown, whereas directed walks should be optimal when the location of favorable habitats is known (Papastamatiou et al., 2011). In new and unfamiliar locations or areas where patches are outside the sensory range of the animal, some form of random-walk must be performed. This might be the case in our study as the environment is composed of two distinct habitats including a restricted reef surrounded by unfamiliar silt habitats. Our results also show that fish may have centers of activity along specific parts of the reef and occasionally visit other habitats such as silt areas (Fig. 6). In accordance with our results, previous research found that individual reef fishes can cluster their activities within small sections of the available linear reef habitat, and those movements within and outside of these home ranges are made along predictable routes (Fox and Bellwood, 2014). Short excursions outside an established center of activity are commonly observed (Kramer and Chapman, 1999, Chateau and Wantiez, 2008b) and generally attributed to 
exploratory movements outside their areas of normal activity or spawning activity. Both species are coral reef attached and it remains unclear why some explore silt habitats where corals are absent.

In conclusion, our study showed that within a MPA, two fish species of separate trophic guilds show different spatial behavior. At the species level, individuals showed behavioral differences and clear diel and

consider multiple species and a large number of individuals in telemetry studies to improve MPA monitoring and effectiveness.

\section{Acknowledgments}

The Fondation d'Entreprise TOTAL and the Ecole Pratique des Hautes Etudes provided financial

support for this study. We thank the Observatoire du Milieu Marin Martiniquais (OMMM) and the Institut

Français de Recherche pour l'Exploitation de la Mer (IFREMER) for technical support. We are grateful to

revisions.

\section{References}

Abecasis, D., e Costa, B. H., Afonso, P., Gonçalves, E. J., Erzini, K. 2015. Early reserve effects linked to small home ranges of a commercial fish, Diplodus sargus, Sparidae. Mar Ecol Prog Ser, 518, 255-266.

Armstrong, J.D., Johnstone, A.D.F., Lucas, M.C., 1992. Retention of intragastric transmitters after voluntary ingestion by captive cod, Gadus morhua L. J. Fish. Biol. 40, 135-137.

Bruggemann, J.H., Kuyper, M.W.M., Breeman, A.M., 1994. Comparative analysis of foraging and habitat use by the sympatric Caribbean parrotfish Scarus vetula and Sparisoma viride. Mar. Ecol. Prog. Ser. 112, 51-66.

Chateau, O., Wantiez, L., 2008a. Human impacts on residency behaviour of spangled emperor, Lethrinus nebulosus, in a marine protected area, as determined by acoustic telemetry. J. Mar. Biol. Assoc. UK 88, 825-829.

Chateau, O., Wantiez, L., 2008b. Movement patterns of four coral reef species in a fragmented habitat in New Caledonia: implications for the design of marine protected area networks. ICES J Mar Sci 66, 50-55

Choat, J.H., Robertson, D.R., Akerman, J.L., Posada, J.M., 2003. An age-based demographic analysis of the Caribbean stoplight parrotfish Sparisoma viride. Mar. Ecol. Prog. Ser. 246, 265-277.

Claudet, J., Osenberg, C.W., Benedetti-Cecchi, L., Domenici, P., García-Charton, J.A., Pérez-Ruzafa, A., Badalamenti, F., Bayle-Sempere, J., Brito, A, Bulleri, F., Culioli, J.M., Dimech, M., Falcón, J.M., Guala, I., Milazzo, M., Sánchez-Meca, J., Somerfield, P.J., Stobart, B., Vandeperre, F., Valle C., Planes, S., 2008. Marine reserves: Size and age do matter. Ecol. Lett. 11, 481-489.

Clarke, K.R., Warwick, R.M., 2001. Change in marine communities: an approach to statistical analysis and interpretation. 5 Primer-E Ltd, Plymouth Marine Laboratory, Plymouth

Cocheret de la Morinière, E., Pollux, B.J.A., Nagelkerken, I., Hemminga, M.A., Huiskes, A.H.L., van der Velde, G., 2003. Ontogenetic dietary changes of coral reef fishes in the mangrove-seagrass-reef continuum: stable isotopes and gut-content analysis. Mar. Ecol. Prog. Ser. 246, 279-289. 
Dahlgren, C.P., Eggleston, D.B., 2000. Ecological processes underlying ontogenetic habitat shifts in a coral reef fish. Ecology. 81, 2227-2240.

Dubin, R.E., Baker, J.D., 1982. Two types of cover-seeking behavior at sunset by the princess parrotfish, Scarus taeniopterus, at Barbados, West Indies. Bull. Mar. Sci. 32, 572-583.

Fox, R.J., Bellwood, D.R., 2011. Unconstrained by the clock? Plasticity of diel activity rhythm in a tropical reef fish, Siganus lineatusi. Funct. Ecol. 25, 1096-1105.

Fox, R.J., Bellwood, D.R., 2014. Herbivores in a small world: network theory highlights vulnerability in the function of herbivory on coral reefs. Funct. Ecol. 28, 642-651.

Garcia, J., Rousseau, Y., Legrand, H., Saragoni, G., Philippe, L., 2014. Spatial and temporal patterns of fish movement in a Martinique MPA: implications for marine reserve design. Mar. Ecol. Prog. Ser. 53, 171185.

Hitt S., Pittman, S.J., Brown, K.A., 2011a. Tracking and mapping sun-synchronous migrations and diel space use patterns of Haemulon sciurus and Lutjanus apodus in the U.S. Virgin Islands. Environ. Biol. Fish. $92,525-538$.

Hitt, S., Pittman, S.J., Nemeth, R.S., 2011b. Diel movements of fish are linked to benthic seascape structure in a Caribbean coral reef ecosystem. Mar. Ecol. Prog. Ser. 427, 275-291

Howard, K.G., Claisse, J.T., Clark, T.B., Boyle, K., Parrish, J.D., 2013. Home range and movement patterns of the Redlip Parrotfish (Scarus rubroviolaceus) in Hawaii. Mar. Biol. 160, 1583-1595.

Jacoby, D.M.P., Brooks, E.J., Croft, D.P., Sims, D.W., 2012. Developing a deeper understanding of animal movements and spatial dynamics through novel application of network analyses. Methods. Ecol. Evol. $3,574-583$.

Koeck, B., Alós, J., Caro, A., Neveu, R., Crec'hriou, R., Saragoni, G., Lenfant P., (2013) Contrasting fish behavior in artificial seascapes with implications for resources conservation. PloS ONE 8(7), e69303.

Kramer, D.L., Chapman, M.R., 1999. Implications of fish home range size and relocation for marine reserve function. Environ. Biol. Fishes. 55, 65-79.

Krumme, U., 2009. Diel and tidal movements by fish and decapods linking tropical coastal ecosystems. In: + Negelkerken I(ed) Ecological connectivity among tropical coastal ecosystems. Springer, New York, pp 271-324.

Lowe, C.G., Topping, D.T., Cartamil, D.P., Papastamatiou, Y.P., 2003. Movement patterns, home range, and habitat utilization of adult kelp bass Paralabrax clathratus in a temperate no-take marine reserve. Mar. Ecol. Prog. Ser. 256, 205-216.

Luo, J.G., Serafy, J.E., Sponaugle, S., Teare, P.B, Kieckbusch, D., 2009. Movement of gray snapper Lutjanus griseus among subtropical seagrass, mangrove, and coral reef habitats. Mar. Ecol. Prog. Ser. 380, 255269.

Marshell, A., Mills, J.S., Rhodes, K.L.J., Mcllwain, J., 2011. Passive acoustic telemetry reveals highly variable home range and movement patterns among unicornfish within a marine reserve. Coral Reefs. 30, 631642.

McFarland, W.N., Ogden, J.C., Lythgoe, J.N., 1979. The influence of light on the twilight migrations of grunts. Environ. Biol. Fish. 4, 9-22.

Meyer, C.G., Holland, K.N., Wetherbee, B.M., Lowe, C.G., 2000. Movement patterns, habitat utilization, home range size and site fidelity of whitesaddle goatfish, Parupeneus porphyreus, in a marine reserve. Environ. Biol. Fish. 59, 235-242.

Meyer, C.G., Holland, K.N., 2005. Movement patterns, home range size and habitat utilization of the bluespine unicornfish, Naso unicornis (Acanthuridae) in a Hawaiian marine reserve. Environ. Biol. Fish. 73, 201210.

Meyer, C.G., 2007. The impacts of spear and other recreational fishers on a small permanent marine protected area and adjacent pulse fished area. Fish. Res. 84, 301-307.

Meyer, C.G, Papastamatiou, Y.P., Clark, T.B., 2010. Differential movement patterns and site fidelity among trophic groups of reef fishes in a Hawaiian marine protected area. Mar. Bio1. 57, 1499-1511.

Mumby, P.J., Wabnitz, C.C., 2002. Spatial patterns of aggression, territory size, and harem size in five sympatric Caribbean parrotfish species. Environ. Biol. Fish. 63, 265-279.

Munro J.L., 2000. Outmigration and movement of tagged coral reef fish in a marine fishery reserve in Jamaica. Proc. Gulf. Caribb. Fish. Inst. 51, 557-568.

Nagelkerken, I., Dorenbosch, M., Verberk, W.C.E.P., Cocheret de la Morinière, E., van der Velde, G., 2000. Day-night shifts of fishes between shallow-water biotopes of a Caribbean bay, with emphasis on the nocturnal feeding of Haemulidae and Lutjanidae. Mar. Ecol. Prog. Ser. 194, 55-64.

Nagelkerken, I., Roberts, C.M., van der Velde, G., Dorenbosch, M., van Riel, M.C., de la Morinière, E.C., Nienhuis, P.H., 2002. How important are mangroves and seagrass beds for coral-reef fish? The nursery hypothesis tested on an island scale. Mar. Ecol. Prog. Ser. 244, 299-305. 
Nathan, R., Getz W.M., Revilla, E., Holyoak, M., Kadmon, R., Saltz, D., Smouse, P.E., 2008. A movement ecology paradigm for unifying organismal movement research. Proc. Natl. Acad. Sci. USA 105, 1905219059.

Newman, M. E., 2004. Analysis of weighted networks. Phys. Rev.E 70: 056131.

Ogden, J.C., Buckman, N.S., 1973. Movements, foraging groups, and diurnal migrations of the striped parrotfish Scarus croicensis Bloch (Scaridae). Ecology. 54, 589-596.

Ogden, J.C., Ehrlich, P.R., 1977. The behaviour of heterotypic resting schools of juvenile grunts (Pomadasyidae). Mar. Biol. 42, 273-280.

Papastamatiou, Y.P., Cartamil, D.P., Lowe C.G., Meyer C.G., Wetherbee B.M., Holland K.N., 2011. Scales of orientation, directed walks and movement path structure in sharks. J. Anim. Ecol. 80, 864-874.

Payne, N.L., Gillanders, B.M., Webber, D.M, Semmens, J.M., 2010. Interpreting diel activity patterns from acoustic telemetry: the need for controls. Mar. Ecol. Prog. Ser. 419, 295-301.

Pittman, S.J, McAlpine, C.A., 2003. Movement of marine fish and decapod crustaceans: process, theory and application. Adv. Mar. Biol. 44, 205-294.

Quinn, T.P, Brodeur, R.D., 1991. Intra-specific variations in the movement patterns of marine animals. Am. Zool. 31, 231-241.

Radford, C.A., Jeffs, A.G., Tindle, C.T., Montgomery, J.C., 2008. Temporal patterns in ambient noise of biological origin from a shallow water temperate reef. Oecologia. 156, 921-929.

Rooker, J.R., Dennis, G.D., 1991. Diel, lunar and seasonal changes in a mangrove fish assemblage off southwestern Puerto Rico. Bull. Mar. Sci. 49, 684-698.

Rooker, J.R., 1995. Feeding ecology of the schoolmaster snapper, Lutjanus apodus (Walbaum), from southwestern Puerto Rico. Bull. Mar. Sci. 56, 881-894.

Stehfest, K.M., Patterson, T.A., Barnett, A., Semmens, J. M., 2015. Markov models and network analysis reveal sex-specific differences in the space-use of a coastal apex predator. Oikos. DOI: 10.1111/oik.01429

Simpfendorfer, C.A., Heupel, M.R., Collins, A.B., 2008. Variation in the performance of acoustic receivers and its implication for positioning algorithms in a riverine setting. Can. J. Fish. Aquat. Sci. 65:482-492.

Taylor, B.M., Mills, J.S., 2013. Movement and spawning migration patterns suggest small marine reserves can offer adequate protection for exploited emperorfishes. Coral Reefs. 32, 1077-1087.

Topping, D.T., Lowe, C.G., Caselle J.E., 2005. Home range and habitat utilization of adult California sheephead, Semicossyphus pulcher (Labridae), in a temperate no-take marine reserve. Mar. Biol. 147, 301-311.

van Rooij, J.M., Kroon, F.J., Videler, J.J., 1996. The social and mating system of the herbivorous reef fish Sparisoma viride: one-male versus multi-male groups. Environ. Biol. Fish. 47, 353-378.

Verweij, M.C., Nagelkerken, I., Hol, K.E.M., van den Beld A.H.J.B., van der Velde G., 2007. Space use of Lutjanus apodus including movement between a putative nursery and a coral reef. Bull. Mar. Sci. 81, 127-138.

Welsh, J.Q., Bellwood, D.R., 2012. Spatial ecology of the steephead parrotfish (Chlorurus microrhinos): an evaluation using acoustic telemetry. Coral Reefs. 31, 55-65.

\section{Figure Legends}

Fig. 1: Map of the study area in Martinique ( $\triangle$ : Artificial reef, $\mathbf{X}$ : Location of Lutjanus apodus capture and $\mathbf{X}$, Location of Sparisoma viride capture). Locations of the VR2W acoustic receivers are displayed (Point: receiver location; Circle: detection range). The artificial reef is indicated and the town of Le Robert is represented by a dark circle.

Fig. 2: Diel detection patterns of 6 Lutjanus apodus captured inside Robert MPA on rocky substrate from December 2011 to November 2012. Horizontal curves show daily sunrise and sunset. Colors of the symbols on the scatterplots correspond to the receiver locations indicated in the map on the top of the figure.

Fig. 3: Diel detection patterns of 5 Sparisoma viride captured inside Robert MPA on rocky substrate from December 2011 to November 2012. Horizontal curves show daily sunrise and sunset. Colors of the symbols on the scatterplots correspond to the receiver locations indicated in the map on the top of the figure. 


\section{ACCEPTED MANUSCRIPT}

537 Fig. 4: a: non-metric multidimensional scaling ordination of space utilization by Lutjanus apodus and Sparisoma

538 viride in the study area. b: Non-metric multidimensional scaling ordination of diurnal and nocturnal space

539 utilization by Lutjanus apodus. c: Non-metric multidimensional scaling ordination of diurnal and nocturnal space

540 utilization by Sparisoma viride.

541 Fig. 5: Boxplot showing the predicted probabilities of presence from the GLMM most parsimonious model for 542 both species as a function of time of day and habitat.

543 Fig. 6: Spatial networks of movements for each fish species with node representing receiver locations and node

544 size and color proportional to the eigenvector centrality computed for the adjacency matrix of between-state

545 transition frequencies. Edges represent frequencies of movement between receivers. For each network, the transition probability matrix is given with colour of the cells related to probabilities. 
Table 1: Descriptive information about tagged individuals and dominant peaks calculated with time series analysis (FFT) for Lutjanus apodus and Sparisoma viride.

\begin{tabular}{|c|c|c|c|c|c|c|c|c|}
\hline Species & Sex & Individuals & $\begin{array}{l}\text { Total } \\
\text { lengh } \\
(\mathrm{cm}) \\
\end{array}$ & $\begin{array}{l}\text { Weight } \\
(\mathrm{g})\end{array}$ & $\begin{array}{c}\text { Number of } \\
\text { days detected }\end{array}$ & $\begin{array}{c}\% \text { of time } \\
\text { within array }\end{array}$ & $\begin{array}{c}\text { Number of } \\
\text { VR2Ws } \\
\text { visited }\end{array}$ & $\begin{array}{l}\text { Dominant } \\
\text { peaks }(\mathrm{h})\end{array}$ \\
\hline L. apodus & & ID\#162 & 23.5 & 200 & 195 & $100 \%$ & 3 & 0 \\
\hline L. apodus & & ID\#169 & 18.5 & 100 & 208 & $98 \%$ & 3 & 24 \\
\hline L. apodus & & ID\#176 & 20 & 120 & 208 & $98.1 \%$ & 2 & 24 \\
\hline L. apodus & & ID\#308 & 19.5 & 120 & 36 & $10.7 \%$ & 2 & 24 \\
\hline L. apodus & & ID\#265 & 22.5 & 150 & 118 & $99.2 \%$ & 4 & 24,12 \\
\hline L. apodus & & ID\#167 & 19.5 & 120 & 208 & $100 \%$ & 3 & 24,8 \\
\hline L. apodus & & ID\#270 & 22.5 & 180 & 57 & $40.4 \%$ & 1 & 0 \\
\hline L. apodus & & ID\#154 & 23.5 & 240 & 3 & $1.5 \%$ & 5 & I \\
\hline L. apodus & & ID\#160 & 19 & 120 & 2 & $0.9 \%$ & 2 & I \\
\hline L. apodus & & ID\#164 & 26.5 & 300 & 6 & $3.1 \%$ & 5 & I \\
\hline L. apodus & & ID\#170 & 22.5 & 200 & 3 & $1.6 \%$ & 3 & l \\
\hline L. apodus & & ID\#171 & 24.5 & 260 & 4 & $2.1 \%$ & 2 & / \\
\hline S. viride & Female & ID\#146 & 19 & 140 & 68 & $31.5 \%$ & 3 & 0 \\
\hline S. viride & Female & ID\#151 & 21.5 & 190 & 215 & $99.5 \%$ & 2 & $24,12,6,4$ \\
\hline S. viride & Male & ID\#165 & 22.5 & 190 & 21 & $9.7 \%$ & 3 & 0 \\
\hline S. viride & Female & ID\#173 & 18 & 100 & 128 & $63.7 \%$ & 3 & 24,8 \\
\hline S. viride & Male & ID\#178 & 21 & 160 & 158 & $73.1 \%$ & 3 & $24,8,4$ \\
\hline S. viride & Male & ID\#174 & 27 & 300 & 21 & $10.1 \%$ & 2 & I \\
\hline S. viride & Male & ID\#142 & 25 & 220 & 10 & $4.6 \%$ & 1 & I \\
\hline S. viride & Male & ID\#144 & 20.5 & 150 & 5 & $2.3 \%$ & 1 & I \\
\hline S. viride & Male & ID\#150 & 19 & 120 & 22 & $10.2 \%$ & 4 & / \\
\hline S. viride & Male & ID\#158 & 17.5 & 100 & 92 & $18.4 \%$ & 2 & I \\
\hline S. viride & Female & ID\#180 & 21 & 160 & 5 & $2.3 \%$ & 2 & I \\
\hline
\end{tabular}


Table 2 : GLMM analyses model comparison results

\begin{tabular}{|c|c|c|c|c|c|c|}
\hline Lutjanus apodus & Model covariates & df & $\operatorname{logLik}$ & $\mathrm{AICc}$ & $\Delta \mathrm{AICc}$ & Weight \\
\hline & Pres $\sim$ Hour + Month + Receiver $+(1 \mid$ Fish $)$ & 46 & -22910.30 & 45912.6 & 0.00 & 1 \\
\hline & Pres $\sim$ Hour + Receiver $+(1 \mid$ Fish $)$ & 35 & -23311.83 & 46693.7 & 781.07 & 0 \\
\hline & Pres $\sim$ Month + Receiver $+(1 \mid$ Fish $)$ & 23 & -24195.18 & 48436.4 & 2523.76 & 0 \\
\hline & Pres $\sim$ Receiver $+(1 \mid$ Fish $)$ & 12 & -24591.27 & 49206.5 & 3293.94 & 0 \\
\hline & Pres $\sim$ Hour + Month $+(1 \mid$ Fish $)$ & 36 & -35003.72 & 70079.4 & 24166.85 & 0 \\
\hline & Pres $\sim$ Hour $+(1 \mid$ Fish $)$ & 25 & -35382.49 & 70815.0 & 24902.37 & 0 \\
\hline & Pres $\sim$ Month $+(1 \mid$ Fish $)$ & 13 & -36103.25 & 72232.5 & 26319.91 & 0 \\
\hline & Pres (1|Fish) & 2 & -36481.94 & 72967.9 & 27055.28 & 0 \\
\hline \multirow[t]{9}{*}{ Sparisoma viride } & & $\mathrm{df}$ & $\operatorname{logLik}$ & $\mathrm{AICc}$ & $\triangle \mathrm{AICc}$ & Weight \\
\hline & Pres $\sim$ Hour + Month + Receiver $+(1 \mid$ Fish $)$ & 46 & -10487.65 & 21067.3 & 0.00 & 1 \\
\hline & Pres $\sim$ Hour + Receiver $+(1 \mid$ Fish $)$ & 35 & -10802.85 & 21675.7 & 608.40 & 0 \\
\hline & Pres $\sim$ Month + Receiver + (1|Fish $)$ & 23 & -10950.27 & 21946.5 & 879.23 & 0 \\
\hline & Pres $\sim$ Receiver $+(1 \mid$ Fish $)$ & 12 & -11261.40 & 22546.8 & 1479.49 & 0 \\
\hline & Pres $\sim$ Hour + Month $+(1 \mid$ Fish $)$ & 36 & -14078.00 & 28228.0 & 7160.68 & 0 \\
\hline & Pres $\sim$ Hour $+(1 \mid$ Fish $)$ & 25 & -14380.69 & 28811.4 & 7744.07 & 0 \\
\hline & Pres $\sim$ Month $+(1 \mid$ Fish $)$ & 13 & -14380.69 & 29040.6 & 7973.27 & 0 \\
\hline & Pres $\sim(1 \mid$ Fish $)$ & 2 & -14809.27 & 29622.5 & 8555.22 & 0 \\
\hline
\end{tabular}




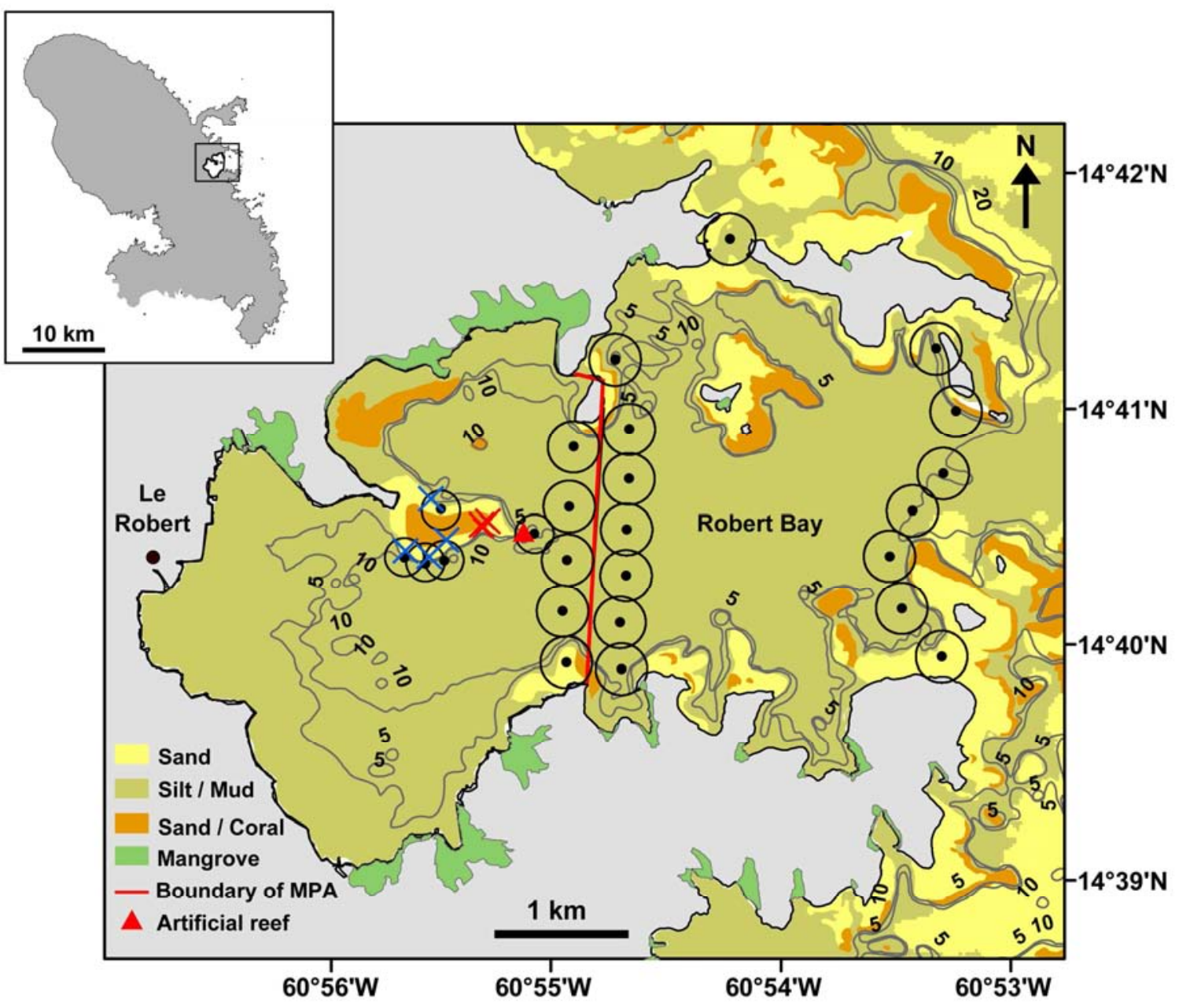



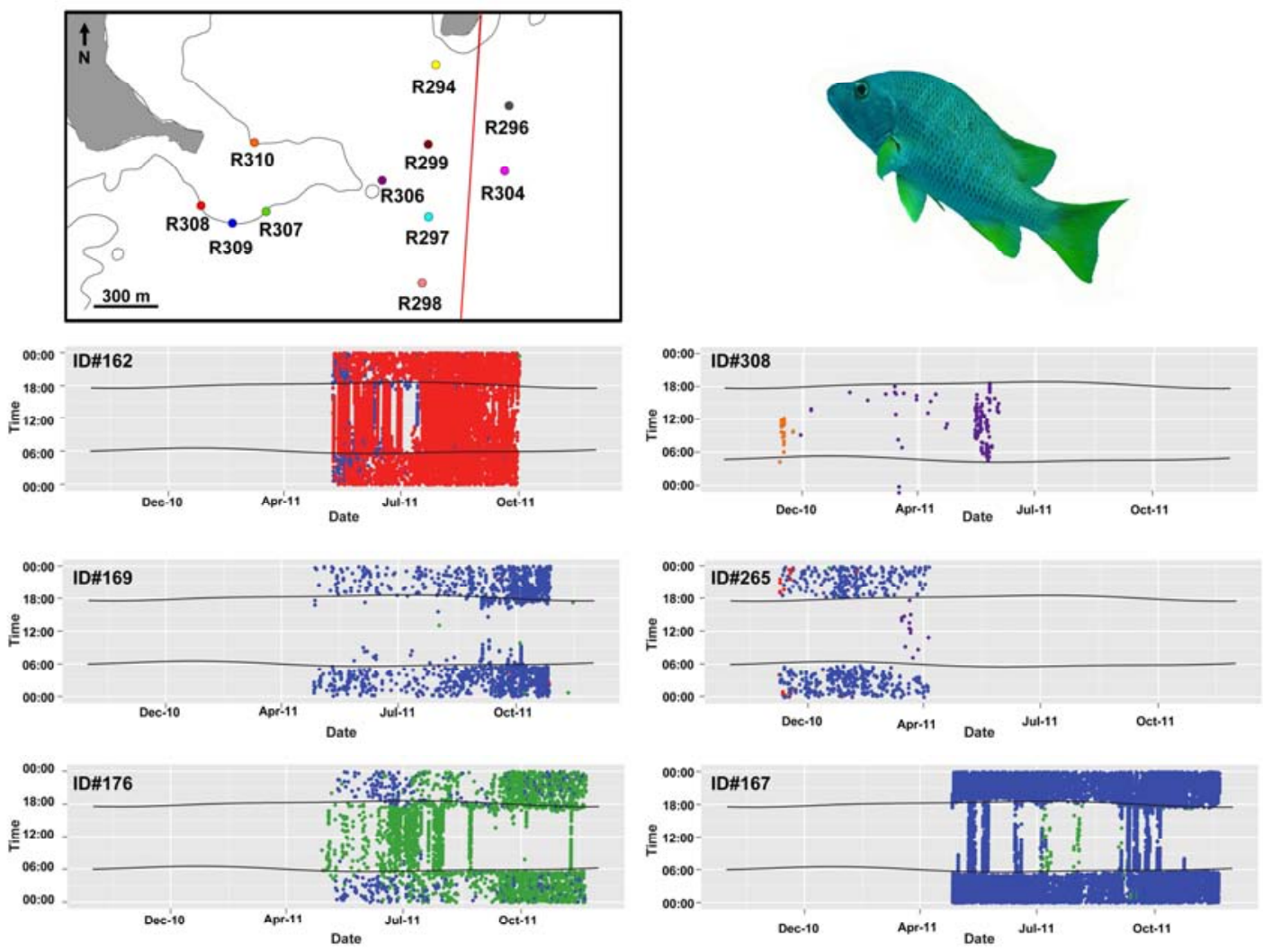

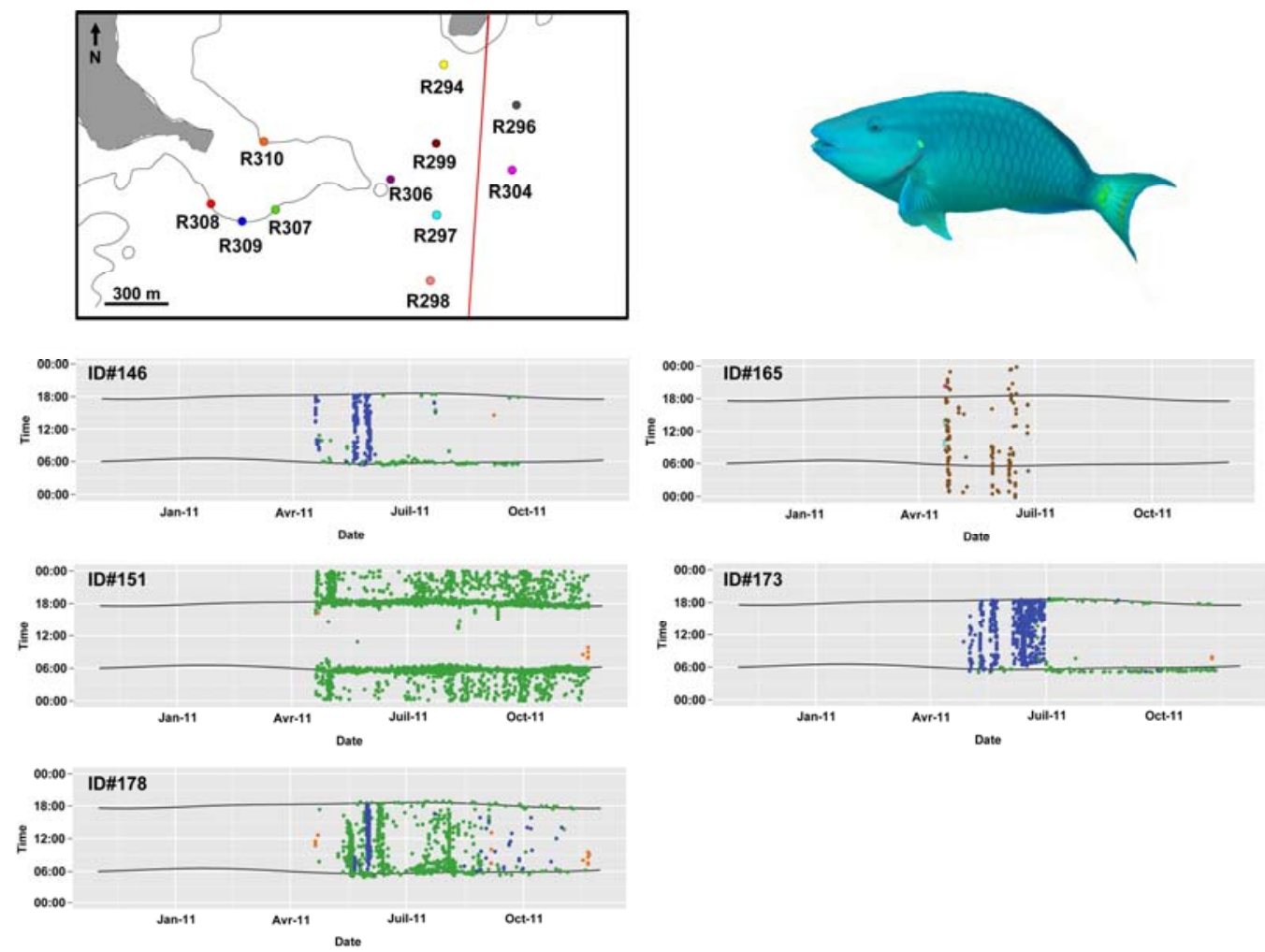


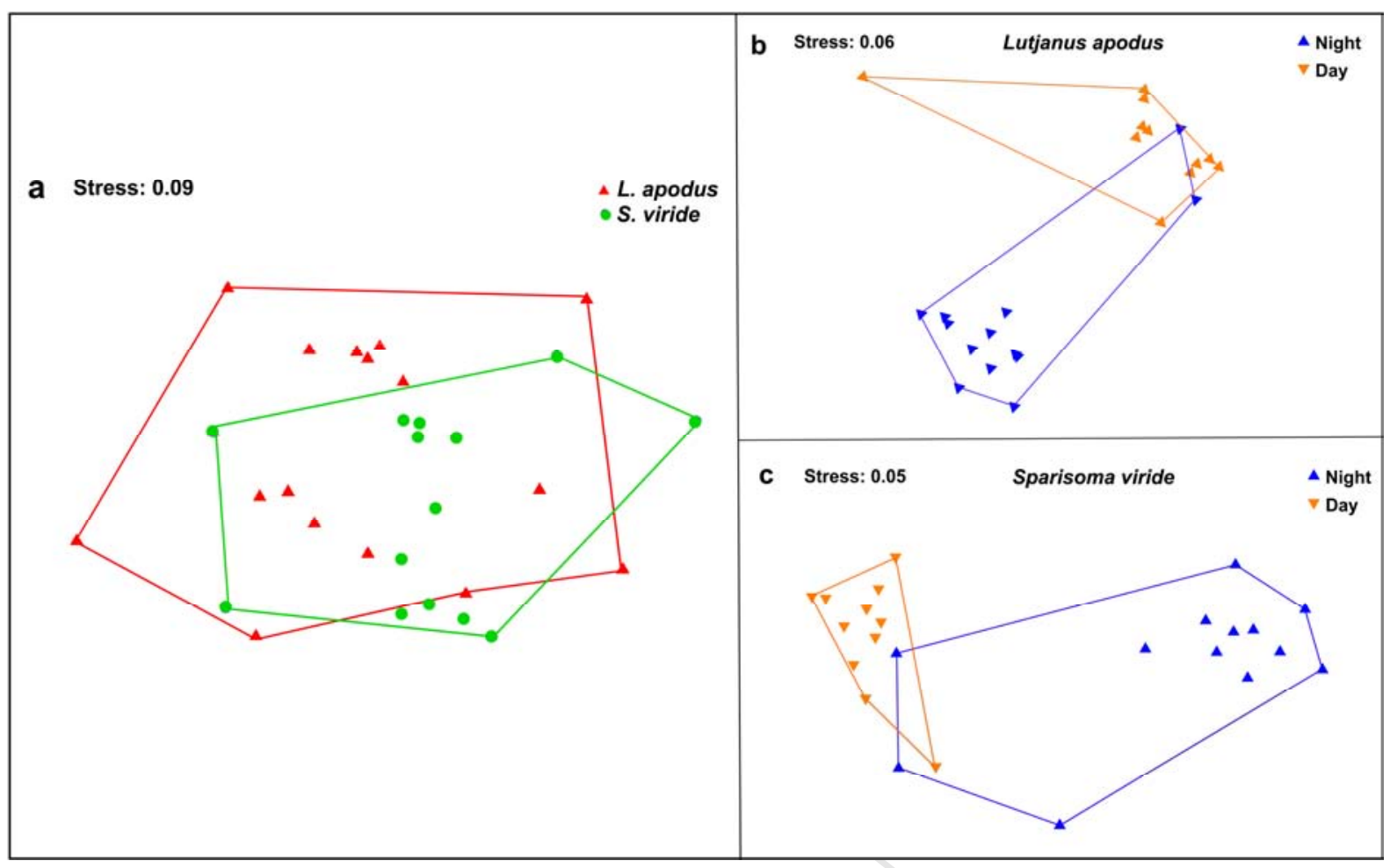




\section{Lutjanus apodus}
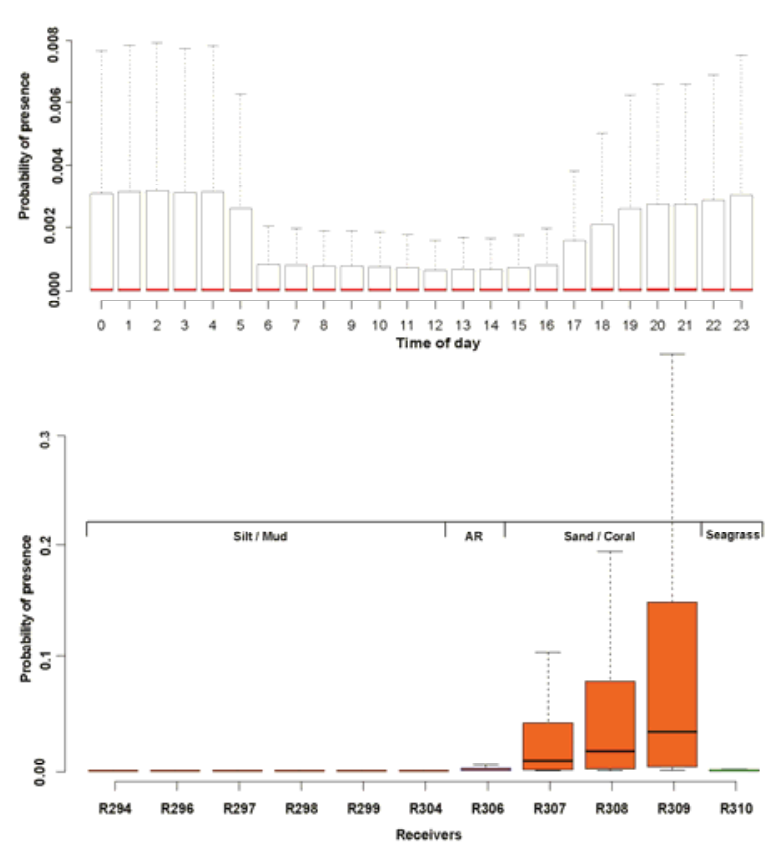

Sparisoma viride
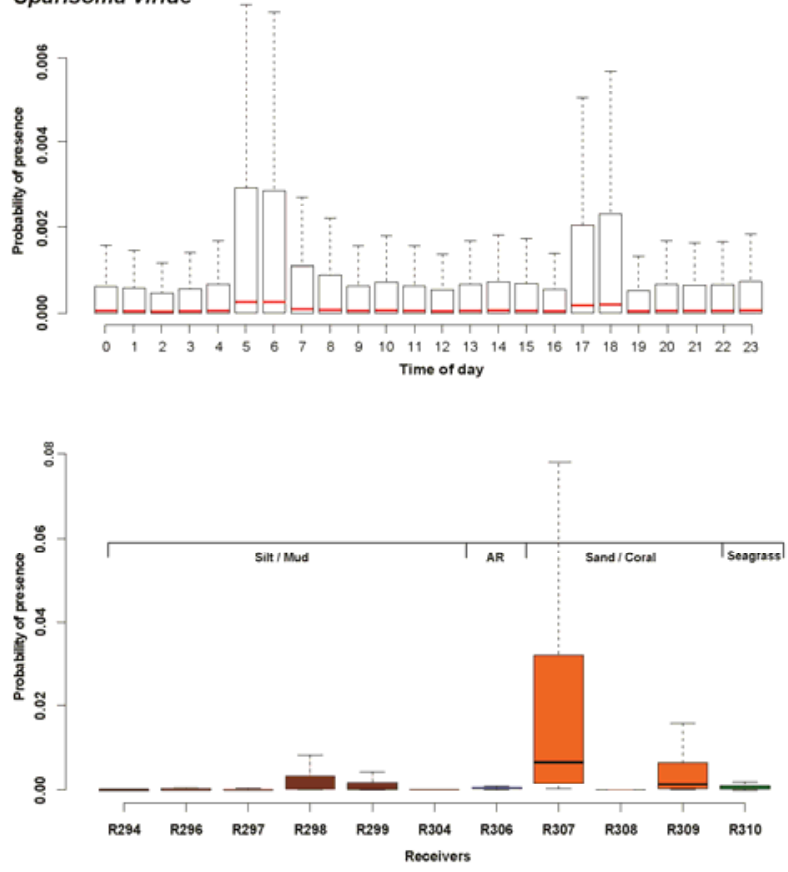

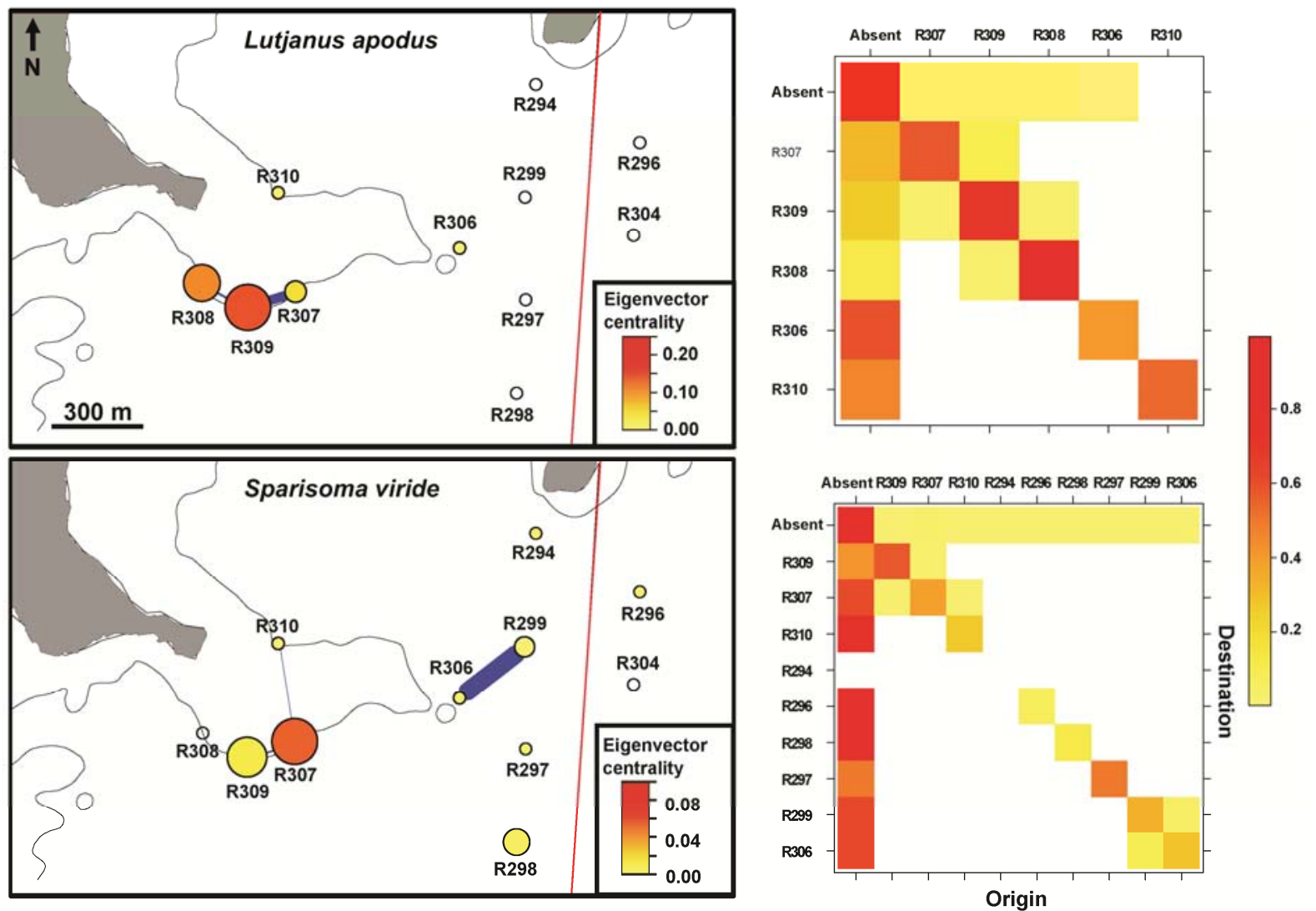

Origin 
Supplementary Table 1: GLMM for model with best fit based on AIC rankings

\begin{tabular}{|c|c|c|c|c|c|c|c|c|c|}
\hline & & & & C. C. & $\mathrm{H}, \mathrm{C}) \mathrm{V}$ & Hesis & P'T & & \\
\hline L. apodus & $\beta \pm \mathrm{SE}$ & & Z & $\mathrm{P}$ & S. viride & $\beta \pm \mathrm{SE}$ & & $\mathrm{Z}$ & $\mathrm{P}$ \\
\hline (Intercept) & $-2.153 e+01$ & $3.499 \mathrm{e}+02$ & -0.062 & 0.950947 & (Intercept) & $-9.360 e+00$ & $1.178 \mathrm{e}+00$ & -7.943 & $1.97 \mathrm{e}-15$ \\
\hline October & $-2.007 \mathrm{e}+00$ & $1.440 \mathrm{e}-01$ & -13.937 & $<2 \mathrm{e}-16$ & February & $1.499 \mathrm{e}-01$ & $2.152 \mathrm{e}-01$ & 0.697 & 0.485914 \\
\hline November & $-2.438 \mathrm{e}+00$ & $1.492 \mathrm{e}-01$ & -16.338 & $<2 \mathrm{e}-16$ & March & $7.518 \mathrm{e}-01$ & $1.921 \mathrm{e}-01$ & 3.914 & $9.07 \mathrm{e}-05$ \\
\hline December & $-5.025 \mathrm{e}-01$ & $1.341 \mathrm{e}-01$ & -3.748 & 0.000178 & April & $-2.850 \mathrm{e}+00$ & $3.367 \mathrm{e}-01$ & -8.464 & $<2 \mathrm{e}-16$ \\
\hline February & $3.545 \mathrm{e}-01$ & $1.098 \mathrm{e}-01$ & 3.229 & 0.001244 & May & $-3.057 \mathrm{e}+00$ & $3.326 \mathrm{e}-01$ & -9.191 & $<2 \mathrm{e}-16$ \\
\hline March & $-3.634 \mathrm{e}-01$ & $1.283 \mathrm{e}-01$ & -2.833 & 0.004617 & June & $-3.189 e+00$ & $3.330 \mathrm{e}-01$ & -9.577 & $<2 \mathrm{e}-16$ \\
\hline April & $-2.867 \mathrm{e}+00$ & $1.735 \mathrm{e}-01$ & -16.524 & $<2 \mathrm{e}-16$ & July & $-3.419 e+00$ & $3.341 \mathrm{e}-01$ & -10.235 & $<2 \mathrm{e}-16$ \\
\hline May & $-2.497 \mathrm{e}+00$ & $1.441 \mathrm{e}-01$ & -17.335 & $<2 \mathrm{e}-16$ & August & $-3.557 \mathrm{e}+00$ & $3.345 \mathrm{e}-01$ & -10.635 & $<2 \mathrm{e}-16$ \\
\hline June & $-2.511 \mathrm{e}+00$ & $1.441 \mathrm{e}-01$ & -17.425 & $<2 \mathrm{e}-16$ & September & $-3.684 \mathrm{e}+00$ & $3.353 \mathrm{e}-01$ & -10.987 & $<2 \mathrm{e}-16$ \\
\hline July & $-2.446 \mathrm{e}+00$ & $1.440 \mathrm{e}-01$ & -16.986 & $<2 \mathrm{e}-16$ & October & $-3.881 \mathrm{e}+00$ & $3.363 \mathrm{e}-01$ & -11.541 & $<2 \mathrm{e}-16$ \\
\hline August & $-2.415 e+00$ & $1.438 \mathrm{e}-01$ & -16.793 & $<2 \mathrm{e}-16$ & November & $-3.982 \mathrm{e}+00$ & $3.411 \mathrm{e}-01$ & -11.676 & $<2 \mathrm{e}-16$ \\
\hline September & $-2.229 \mathrm{e}+00$ & $1.435 \mathrm{e}-01$ & -15.529 & $<2 \mathrm{e}-16$ & December & $-6.606 \mathrm{e}-01$ & $2.663 \mathrm{e}-01$ & -2.480 & 0.013132 \\
\hline hour1 & $2.234 \mathrm{e}-02$ & $7.078 \mathrm{e}-02$ & 0.316 & 0.752277 & hour1 & $-7.730 \mathrm{e}-02$ & $1.733 \mathrm{e}-01$ & -0.446 & 0.655535 \\
\hline hour10 & $-1.391 \mathrm{e}+00$ & $9.445 \mathrm{e}-02$ & -14.730 & $<2 \mathrm{e}-16$ & hour2 & $-3.000 \mathrm{e}-01$ & $1.831 \mathrm{e}-01$ & -1.639 & 0.101195 \\
\hline hour11 & $-1.430 \mathrm{e}+00$ & $9.552 \mathrm{e}-02$ & -14.976 & $<2 \mathrm{e}-16$ & hour3 & $-1.088 \mathrm{e}-01$ & $1.746 \mathrm{e}-01$ & -0.623 & 0.532983 \\
\hline hour12 & $-1.548 \mathrm{e}+00$ & $9.893 \mathrm{e}-02$ & -15.644 & $<2 \mathrm{e}-16$ & hour4 & $6.799 \mathrm{e}-02$ & $1.677 \mathrm{e}-01$ & 0.405 & 0.685224 \\
\hline hour13 & $-1.484 \mathrm{e}+00$ & $9.705 e-02$ & -15.295 & $<2 \mathrm{e}-16$ & hour5 & $1.536 \mathrm{e}+00$ & $1.367 \mathrm{e}-01$ & 11.234 & $<2 \mathrm{e}-16$ \\
\hline hour14 & $-1.505 e+00$ & $9.766 \mathrm{e}-02$ & -15.410 & $<2 \mathrm{e}-16$ & hour6 & $1.511 \mathrm{e}+00$ & $1.370 \mathrm{e}-01$ & 11.030 & $<2 \mathrm{e}-16$ \\
\hline hour15 & $-1.437 \mathrm{e}+00$ & $9.570 \mathrm{e}-02$ & -15.019 & $<2 \mathrm{e}-16$ & hour7 & $5.501 \mathrm{e}-01$ & $1.532 \mathrm{e}-01$ & 3.590 & 0.000331 \\
\hline hour16 & $-1.329 \mathrm{e}+00$ & $9.280 \mathrm{e}-02$ & -14.321 & $<2 \mathrm{e}-16$ & hour8 & $3.448 \mathrm{e}-01$ & $1.587 \mathrm{e}-01$ & 2.172 & 0.029871 \\
\hline hour17 & $-6.634 \mathrm{e}-01$ & $7.914 \mathrm{e}-02$ & -8.382 & $<2 \mathrm{e}-16$ & hour9 & $-2.330 \mathrm{e}-03$ & $1.703 \mathrm{e}-01$ & -0.014 & 0.989088 \\
\hline hour18 & $-3.846 \mathrm{e}-01$ & $7.519 \mathrm{e}-02$ & -5.116 & 3.12e-07 & hour10 & $1.341 \mathrm{e}-01$ & $1.654 \mathrm{e}-01$ & 0.811 & 0.417453 \\
\hline hour19 & $-1.688 \mathrm{e}-01$ & $7.268 \mathrm{e}-02$ & -2.322 & 0.020215 & hour11 & $-2.314 \mathrm{e}-03$ & $1.703 \mathrm{e}-01$ & -0.014 & 0.989163 \\
\hline hour2 & $3.235 \mathrm{e}-02$ & $7.072 \mathrm{e}-02$ & 0.457 & 0.647359 & hour12 & $-1.413 e-01$ & $1.759 \mathrm{e}-01$ & -0.803 & 0.421869 \\
\hline hour20 & $-1.144 \mathrm{e}-01$ & $7.211 \mathrm{e}-02$ & -1.587 & 0.112591 & hour13 & $6.799 \mathrm{e}-02$ & $1.677 \mathrm{e}-01$ & 0.405 & 0.685227 \\
\hline hour21 & $-1.134 \mathrm{e}-01$ & $7.208 \mathrm{e}-02$ & -1.573 & 0.115785 & hour14 & $1.469 \mathrm{e}-01$ & $1.650 \mathrm{e}-01$ & 0.891 & 0.373095 \\
\hline hour22 & $-6.817 \mathrm{e}-02$ & $7.167 \mathrm{e}-02$ & -0.951 & 0.341502 & hour15 & $9.491 \mathrm{e}-02$ & $1.668 \mathrm{e}-01$ & 0.569 & 0.569292 \\
\hline hour23 & $-1.736 e-02$ & $7.118 \mathrm{e}-02$ & -0.244 & 0.807273 & hour16 & $-1.249 \mathrm{e}-01$ & $1.752 \mathrm{e}-01$ & -0.713 & 0.476035 \\
\hline hour3 & 8.62 & $7.092 \mathrm{e}-02$ & 0.122 & 0.903213 & hour17 & $1.172 \mathrm{e}+00$ & $1.412 \mathrm{e}-01$ & 8.301 & $<2 \mathrm{e}-16$ \\
\hline hour4 & $2.122 \mathrm{e}-02$ & $7.084 \mathrm{e}-02$ & 0.299 & 0.764559 & hour18 & $1.292 \mathrm{e}+00$ & $1.396 \mathrm{e}-01$ & 9.255 & $<2 \mathrm{e}-16$ \\
\hline hour5 & $-1.648 \mathrm{e}-01$ & $7.265 \mathrm{e}-02$ & -2.268 & 0.023326 & hour19 & $-1.745 \mathrm{e}-01$ & $1.773 \mathrm{e}-01$ & -0.984 & 0.325090 \\
\hline hour6 & $-1.293 \mathrm{e}+00$ & $9.188 \mathrm{e}-02$ & -14.076 & $<2 \mathrm{e}-16$ & hour20 & $6.796 \mathrm{e}-02$ & $1.677 \mathrm{e}-01$ & 0.405 & 0.685325 \\
\hline hour7 & $-1.329 e+00$ & $9.280 \mathrm{e}-02$ & -14.321 & $<2 \mathrm{e}-16$ & hour21 & $4.036 \mathrm{e}-02$ & $1.687 \mathrm{e}-01$ & 0.239 & 0.810968 \\
\hline hour8 & $-1.366 \mathrm{e}+00$ & $9.377 \mathrm{e}-02$ & -14.570 & $<2 \mathrm{e}-16$ & hour22 & $5.429 \mathrm{e}-02$ & $1.682 \mathrm{e}-01$ & 0.323 & 0.746914 \\
\hline hour9 & $-1.366 \mathrm{e}+00$ & $9.377 \mathrm{e}-02$ & -14.567 & $<2 \mathrm{e}-16$ & hour23 & $1.581 \mathrm{e}-01$ & $1.645 \mathrm{e}-01$ & 0.961 & 0.336764 \\
\hline R296 & $-4.191 \mathrm{e}+00$ & $2.866 \mathrm{e}+03$ & -0.001 & 0.998833 & R296 & $2.486 \mathrm{e}+00$ & $1.041 \mathrm{e}+00$ & 2.388 & 0.016935 \\
\hline R297 & $1.241 \mathrm{e}+01$ & $3.499 \mathrm{e}+02$ & 0.035 & 0.971711 & $\mathrm{R} 297$ & $1.387 \mathrm{e}+00$ & $1.118 \mathrm{e}+00$ & 1.240 & 0.214987 \\
\hline R298 & $-4.481 \mathrm{e}+00$ & $3.306 \mathrm{e}+03$ & -0.001 & 0.998919 & $\mathrm{R} 298$ & $5.378 \mathrm{e}+00$ & $1.003 \mathrm{e}+00$ & 5.364 & 8.13e-08 \\
\hline R299 & $-4.359 e+00$ & $3.114 \mathrm{e}+03$ & -0.001 & 0.998883 & R299 & $4.721 \mathrm{e}+00$ & $1.005 \mathrm{e}+00$ & 4.699 & $2.62 \mathrm{e}-06$ \\
\hline R304 & $1.172 \mathrm{e}+01$ & $3.499 \mathrm{e}+02$ & 0.033 & 0.973291 & $\mathrm{R} 304$ & $-1.438 \mathrm{e}+01$ & $1.324 \mathrm{e}+03$ & -0.011 & 0.991338 \\
\hline R306 & $1.612 \mathrm{e}+01$ & $3.499 \mathrm{e}+02$ & 0.046 & 0.963262 & R306 & $3.047 \mathrm{e}+00$ & $1.024 \mathrm{e}+00$ & 2.976 & 0.002921 \\
\hline R307 & $1.913 \mathrm{e}+01$ & $3.499 \mathrm{e}+02$ & 0.055 & 0.956404 & R307 & $7.633 e+00$ & $1.000 \mathrm{e}+00$ & 7.630 & $2.35 \mathrm{e}-14$ \\
\hline R308 & $1.978 \mathrm{e}+01$ & $3.499 \mathrm{e}+02$ & 0.057 & 0.954919 & $\mathrm{R} 308$ & $-1.337 \mathrm{e}+01$ & $8.014 \mathrm{e}+02$ & -0.017 & 0.986686 \\
\hline R309 & $2.048 \mathrm{e}+01$ & $3.499 e+02$ & 0.059 & 0.953316 & R309 & $6.015 \mathrm{e}+00$ & $1.001 \mathrm{e}+00$ & 6.007 & 1.89e-09 \\
\hline R310 & $1.466 \mathrm{e}+01$ & $3.499 \mathrm{e}+02$ & 0.042 & 0.966578 & R310 & $3.917 \mathrm{e}+00$ & $1.010 \mathrm{e}+00$ & 3.878 & 0.000105 \\
\hline \multicolumn{6}{|l|}{ Random } & Random effects & cts & jar & $3.05 \pm 1.747$ \\
\hline
\end{tabular}

